\title{
A PRODUÇÃO ASSOCIADA EM COMUNIDADES E POVOS TRADICIONAIS EM MATO GROSSO: PESQUISAS E REFLEXÕES COLETIVAS DO GEPTE/UFMT ${ }^{1}$
}

\author{
Edson Caetano ${ }^{2}$ \\ Anatália Daiane de Oliveira Ramos 3 \\ Eva Emília Freire do Nascimento Azevedo ${ }^{4}$
}

Resumo

Tendo como referência o materialismo histórico dialético, este texto visa analisar a produção associada como forma de produzir a existência de povos e comunidades tradicionais - MT, a partir de pesquisas desenvolvidas pelo Grupo de Estudos e Pesquisas sobre Trabalho e Educação, da UFMT. Refletimos acerca da produção associada expressa pelos povos e comunidades tradicionais que questionam os ditames da sociedade capitalista e podem contribuir para a construção de uma sociedade pautada na existência solidária e igualitária entre os seres humanos, bem como, respeito aos demais seres vivos e a "Pachamama".

Palavras-chave: trabalho-educação; povos e comunidades tradicionais; produção associada

\section{LA PRODUCCIÓN ASOCIADA EN COMUNIDADES Y PUEBLOS TRADICCIONALES EN MATO GROSSO: INVESTIGACIONES Y REFLEXIONES COLECTIVAS DE GEPTE/UFMT}

\section{Resumen}

En el marco del materialismo histórico dialéctico, este texto busca analizar la producción asociada como forma de producir la existencia de pueblos y comunidades tradicionales - MT -, a partir de las investigaciones desarrolladas por el Grupo de Estudios e Investigaciones sobre Trabajo y Educación, de la UFMT. Reflexionamos sobre la producción asociada expresadas por las personas y las comunidades tradicionales que cuestionan los dictados de la sociedad capitalista y pueden contribuir a la construcción de una sociedad basada en la solidaridad y la igualdad entre los seres humanos, así como el respeto de los otros seres vivos y la "Pachamama".

Palabras clave: trabajo-educación; pueblos y comunidades tradicionales; producción asociada.

1DOI: https://doi.org/10.22409/tn.16i31.p27376

${ }^{2}$ Doutor em Educação pela Universidade Estadual de Campinas (UNICAMP) e professor do Instituto de Educação (IE) da Universidade Federal de Mato Grosso (UFMT). Mestre em Educação pela UNICAMP. Graduado em Ciências Sociais pela PUCCAMP. Líder do Grupo de Estudos e Pesquisas sobre Trabalho e Educação (GEPTE). E-mail: caetanoedeson@hotmail.com.

${ }^{3}$ Pedagoga e mestra em Psicologia pela Fundação Universidade Federal de Rondônia (UNIR). Doutoranda em Educação pela UFMT. Pesquisadora do Grupo de Pesquisa de Educação na Amazônia (GPEA). Participante do GEPTE. Bolsista CAPES. E-mail: anataliadaiane@hotmail.com.

${ }^{4}$ Assistente social e mestra em Serviço Social pela Universidade Federal da Paraíba (UFPB). Doutoranda em Educação da UFMT. Professora do Departamento de Serviço Social na UFMT. Participante do GEPTE. E-mail: evemilia@yahoo.com.br. 


\section{Introdução}

A literatura sobre os povos e comunidades tradicionais e suas características (específicas e comuns) é vasta, entre algumas autoras e autores estão: Brandão e Borges (2007), Brandão e Leal (2012), Cruz (2013), Diegues et al. (2000), Caetano e Neves (2014), Santos (2013) e Souza e Brandão (2012).

Apesar disso, a ampliação das investigações que se ocupem da existência dos povos e comunidades tradicionais se faz necessária, sobretudo por evidenciarem elementos questionadores do modo de produção capitalista, podendo assim, contribuir para a construção de um outro modelo societário ancorado na sociedade dos produtores livremente associados.

Desta forma, partindo do materialismo histórico dialético, o presente texto tem como objetivo analisar a produção da existência de povos e comunidades

tradicionais de Mato Grosso, a partir das pesquisas desenvolvidas no Grupo de Estudos e Pesquisas sobre Trabalho e Educação (GEPTE), do Programa de PósGraduação em Educação (PPGE) da Universidade Federal de Mato Grosso (UFMT).

Organizamos o texto da seguinte forma: na primeira parte, refletimos inicialmente, acerca da centralidade do trabalho enquanto elemento fundante do ser humano e posteriormente, sobre o trabalho como princípio educativo. Na segunda seção examinamos as investigações produzidas no âmbito do GEPTE/UFMT no tocante à produção associada, evidenciando as motivações que nos fazem voltar o

nosso olhar para essa temática. Na terceira parte compartilhamos impressões e resultados concernentes às pesquisas desenvolvidas pelo GEPTE, realizadas junto aos povos e comunidades tradicionais. E finalmente, tecemos considerações a partir das notas de pesquisa que nortearam a produção coletiva do GEPTE quanto as práticas econômico-culturais expressas pelos povos e comunidades tradicionais.

\section{A centralidade do trabalho e a relação trabalho-educação}

Tomando como referência os pressupostos marxiano e marxista, partimos da perspectiva ontocriativa do trabalho enquanto atividade vital do ser humano. Nesse sentido, Antunes (2009a, p. 136), afirma que o trabalho tem um caráter transitório, 
pois é inter-relação do ser humano com a natureza e com seus pares - período que se caracteriza pelo "[...] salto ontológico das formas pré-humanas para o ser social".

O uso da mão e o domínio sobre a natureza através do trabalho permitiram que o ser humano descobrisse nos objetos "novas propriedades até então desconhecidas" (ENGELS, 2013, p. 17). Assim, também foram desenvolvidas outras habilidades, como a fala e os cinco sentidos. Segundo Marx (2013, p. 31),

[...] o trabalho é um processo entre o homem e a natureza, um processo em que o homem, por sua própria ação, media, regula e controla seu metabolismo com a natureza. [...] Ele põe em movimento as forças naturais pertencentes à sua corporalidade, braços e pernas, cabeça e mão, a fim de apropriar-se da matéria natural numa forma útil para sua própria vida.

Por isso, diz-se que o ser humano transforma a natureza e também a si mesmo, submetendo-a ao seu domínio e criando conhecimentos, objetivos, objetos, necessidades, desenvolvendo seu potencial, suas habilidades etc. Tudo isso se dá através da ideação, ou seja, de um projeto que já aconteceu antes, na sua imaginação - diferença apontada por Marx (2013) entre o ser humano e os demais seres vivos.

Para Marx (2013, p. 33), a terra e a água são "[...] como fonte original de víveres e meios já prontos de subsistência para o homem". A terra, como "despensa natural", fornece aos seres humanos não apenas as condições para sua existência, mas também os meios de trabalho. Todavia, se em tempos mais remotos, o ser humano tinha essa relação e contato direto com a natureza para suprimento de suas necessidades, a realidade do trabalho foi profundamente alterada a partir da posse privada da terra.

Sem a intenção aqui de aprofundar a trajetória histórica da humanidade, destacamos a partir de Saviani (2007), dois momentos que foram cruciais para a mudança no mundo do trabalho: o advento do capitalismo e a revolução industrial. Para o autor,

[...] o avanço das forças produtivas, ainda sob as relações feudais, intensificou o desenvolvimento da economia medieval, provocando a geração sistemática de excedentes e ativando o comércio. Esse processo desembocou na organização da produção especificamente 
voltada para a troca, dando origem à sociedade capitalista. Nessa nova forma social, inversamente ao que ocorria na sociedade formal, é a troca que determina o consumo. (SAVIANI, 2007, p. 158).

Assim, as relações entre homens e mulheres também mudaram, pois deixaram de ser fundadas nos laços naturais para se efetivarem por laços "[...] propriamente sociais, isto é, produzidos pelos próprios homens. Trata-se da sociedade contratual, cuja base é o direito positivo e não mais o direito natural ou consuetudinário" (SAVIANI, 2007, p. 158).

Nas relações sociais de produção, a exploração passou a ser cada vez mais presente, decorrente da separação entre classes. Assim, os que detêm o capital e os que detêm a força de trabalho, não possuem condições iguais - embora seja esse o discurso liberal (FRIGOTTO, 2010).

A Revolução Industrial (1820-1840) é marcada pela presença da maquinaria e a não exigência de qualificação para certos ofícios - que passaram a ser executados pelas máquinas. Isso significou menos utilização da força de trabalho humana, que se tornou coadjuvante (SAVIANI, 2007). Nesse sentido, a criação das máquinas afetou as outras criaturas - também criadoras -, cada vez mais distanciadas das possibilidades de satisfação das suas necessidades. Assim,

[...] os ingredientes intelectuais antes indissociáveis do trabalho manual humano, como ocorria no artesanato, dele destacam-se, indo incorporar-se às máquinas. Por esse processo, dá-se a mecanização das operações manuais, sejam elas executadas pelas próprias máquinas ou pelos homens, que passam a operar manualmente como sucedâneos das máquinas. Pode-se, pois, estabelecer uma relação entre o caráter abstrato do trabalho assim organizado, com o caráter abstrato próprio das atividades intelectuais: o trabalho tornouse abstrato, isto é, simples e geral, porque organizado de acordo com os princípios científicos, também eles abstratos, elaborados pela inteligência humana. (SAVIANI, 2007, p. 158).

Uma contradição inerente ao modo de produção capitalista é a produção de riqueza de uns para apropriação da riqueza, por outros. Os que produzem se tornam mais pobres e, também, mercadorias. Nas palavras de Marx (2008, p. 80, itálico do autor), 
O trabalhador se torna tanto mais pobre quanto mais riqueza produz, quanto mais a sua produção aumenta em poder e extensão. $O$ trabalhador se torna uma mercadoria tão mais barata quanto mais mercadorias cria. Com a valorização do mundo das coisas (Sachenwelt) aumenta em proporção direta a desvalorização do mundo dos homens (Menschenwelt). O trabalho não produz somente mercadorias; ele produz a si mesmo e ao trabalhador como uma mercadoria, e isto na medida em que produz, de fato, mercadorias em geral.

No século $\mathrm{XX}$, diversos acontecimentos redesenharam os rumos do capitalismo: a sua crise (1929-1932); as tentativas de encontrar respostas para ela, através de maior intervenção do Estado na economia; a segunda guerra mundial (1939-1945), os trinta anos gloriosos do capitalismo, dentre outras.

Antunes (2009a, p. 31, itálico do autor) explica que, após um período de acumulação de capitais, na década de 1970 o capitalismo começa a evidenciar uma nova crise marcada pela "queda da taxa de lucro", pelo "esgotamento do padrão de acumulação taylorista/fordista de produção"; pela "hipertropia da esfera financeira", pela maior "concentração de capitais graças às fusões entre as empresas monopolistas e oligopolistas"; pela crise do Welfare State; e pelo incremento acentuado das privatizações.

Essas mudanças foram - e são - sentidas pelos trabalhadores e trabalhadoras de forma cada vez mais perversa. Nesse sentido, Antunes (2009b), afirma que o trabalho que deveria ser fonte de humanidade, fez - e faz - com que homens e mulheres sejam desumanizados, pois na sociedade capitalista, o trabalho transformou-se em trabalho assalariado, fetichizado, alienado, estranhado e meio de subsistência.

As transformações no mundo do trabalho: redução do trabalho estável; aumento do trabalho terceirizado e feminino, subcontratos, trabalhadores part-time; alterações no setor de serviços; trabalho a domicílio; exclusão de idosos (ANTUNES, 2009a; ALVES, 2004; ANTUNES, 2009b), além da reforma trabalhista recentemente aprovada, são exemplos do cenário contemporâneo.

Embora o trabalho na perspectiva do modo de produção capitalista condicione homens e mulheres aos seus preceitos e intentos, educando-os com seus padrões de comportamento, de utilização do tempo e de pensamento que não os agrega enquanto coletivo, existe outra perspectiva de trabalho. Essa está relacionada a um 
diferente modo de produzir a existência, no qual a educação não é utilizada a fim de inculcar no ser humano valores, padrões e ideologia correspondentes ao interesse do capital, mas de construção de outra possibilidade de ser e existir no mundo, conforme tratamos na subseção a seguir.

\section{Trabalho e educação: possibilidades e desafios}

Embora o trabalho carregue consigo uma série de características negativas comuns ao modo de produção capitalista, como, por exemplo, aquele que nos rouba o tempo de sermos mais do que trabalhadores e trabalhadoras; que explora nossa força e energia; que nos condiciona a um tempo que não é necessariamente o nosso; que não permite que entendamos a complexidade do todo e das relações que nos circundam -, ele está intrinsicamente relacionado à educação.

Saviani (2007) afirma que, no processo de tornar-se homem, o ser humano cria a si mesmo, produz a sua própria existência, educar a si e às outras gerações, por isso, a origem da educação está relacionada à origem do próprio homem. É o trabalho o mediador desse com a natureza "no processo de criação e recriação da realidade humano-social” (TIRIBA; PICANÇO, 2010, p. 20).

Segundo Saviani (2007, p. 155), “o desenvolvimento da produção conduziu à divisão do trabalho e, daí, à apropriação privada da terra, provocando a ruptura da unidade vigente nas comunidades primitivas". Com a separação dos homens e mulheres em classes, a educação também sofreu divisão, passando a ser uma para a classe dominante - voltada às artes, exercícios físicos etc. - e outra, para a dominada - relacionada ao próprio processo de trabalho.

A escola nascida na antiguidade foi se "[...] complexificando, alargando-se até atingir, na contemporaneidade, a condição de forma principal e dominante de educação, convertendo-se em parâmetro e referência para aferir todas as demais formas de educação" (SAVIANI, 2007, p. 156). Ela foi também subordinada aos interesses do modo de produção capitalista, a fim de reproduzir o seu metabolismo, adequando - através de seus conteúdos e instrumentalidade - homens e mulheres a um padrão previamente estabelecido (FRIGOTTO, 2010).

Caetano (2011) destaca que, devido a reestruturação produtiva e seus impactos, a partir da década de 1980 diversas estratégias de trabalho e 
sobrevivência foram (re)criadas por uma parcela da classe trabalhadora, especialmente no âmbito da economia (popular) solidária. Muitas dessas iniciativas se apresentaram - e ainda se apresentam - como possibilidades para a existência de outra forma de organização do trabalho.

Dentre elas, podemos destacar a Produção Associada, que segundo Tiriba (2008, p. 81),

[...] está relacionada a associativismo, entendido como um conjunto de práticas sociais informais ou instituídas desenvolvidas por grupos que se organizam em torno dos ideais e objetivos que compartilham. [...] o associativismo caracteriza-se pela construção de laços sociais calcados na confiança, cooperação e reciprocidade, o que confere aos seus membros o sentimento de pertencimento ao grupo. Quanto à produção associada, ela pode ser entendida de duas maneiras, não necessariamente excludentes: quer como trabalho associativo ou processo em que os trabalhadores se associam na produção de bens e serviços, quer como a unidade econômica básica da "sociedade dos produtores livres associados".

$\mathrm{Na}$ Produção Associada, o trabalho não é alienado nem alienante; a mercadoria não se separa do produtor; inexiste a propriedade individual dos meios de produção e a mais-valia, possibilitando que os trabalhadores e trabalhadoras possam construir de forma coletiva uma nova concepção de mundo, de trabalho e de existência.

Nos espaços da Produção Associada, nota-se a relação intrínseca da educação, da produção de conhecimento e de saberes decorrentes da experiência. Por isso diz-se que,

Conceber a educação e os saberes numa perspectiva ampliada, ou seja, que não se restrinja ao espaço da escola, não implica desconsiderar a importância da reflexão acerca da educação formal, não se trata de estabelecer critérios valorativos entre a educação formal e a educação não formal. Trata-se isto sim, do reconhecimento da existência de espaços diversos aonde os saberes podem ser construídos e dentre esses múltiplos espaços destacamos o da produção ou do trabalho [...]. (CAETANO, 2011, p. 8).

Para além de contribuir com uma crítica ao modo de produção capitalista e as mazelas decorrente do mesmo, a produção e os saberes desse outro modo de organização do trabalho "[...] reforçam o sentimento de pertencimento ao grupo e a 
vontade de manter uma cultura ligada à questão da terra, o que possibilita que eles lutem coletivamente contra possíveis problemas sociais, econômicos, territoriais e culturais" (CAETANO, 2011, p. 15).

\title{
Povos e comunidades tradicionais: possíveis conceitualizações
}

O Grupo de Estudos e Pesquisas sobre Trabalho e Educação (GEPTE), foi criado em 2010, vinculado à Linha de Pesquisa "Movimentos sociais, política e educação popular" do Programa de Pós-Graduação em Educação (PPGE) da UFMT.

Os estudos desenvolvidos no âmbito do GEPTE "[...] analisam as relações entre trabalho e educação presentes nos processos de produzir a vida associativamente, em especial nas chamadas 'comunidades tradicionais' da baixada Cuiabana (Mato Grosso)" (CAETANO, 2011, p. 8-9).

Neste sentido, as pesquisas se debruçam sobre os fundamentos econômicos, culturais, políticos e sociais do trabalho e dos processos formativos humanos, "[...] concebendo o trabalho não apenas no seu sentido ontológico, mas, sobretudo como princípio educativo" (CAETANO; NEVES, 2014, p. 597).

\begin{abstract}
A partir da centralidade do trabalho e do seu princípio educativo, surge no interior do referido Grupo de Pesquisa uma dupla preocupação: de um lado, a tentativa de compreensão dos sentidos do trabalho como condição natural do homem e a sua possibilidade educativa; e de outro, a preocupação reflexiva sobre a configuração assumida pelo trabalho no modo de produção capitalista [...] (CAETANO; NEVES, 2014, p. 597).
\end{abstract}

Evidencia-se, assim, que a divisão do trabalho, a distribuição das riquezas, as relações de poder, as questões de gênero, as relações com a comunidade local e com os movimentos populares, os processos de decisão, os objetivos da produção associada, a concepção de mundo, a resistência, a preocupação com o meio ambiente e a utilização do tempo, são alguns dos aspectos analisados pelas e pelos integrantes do Grupo (CAETANO, 2011).

$O$ intuito do GEPTE é questionar as premissas do modo de produção capitalista (CAETANO, 2011), dar visibilidade às formas de produção da existência dos povos e comunidades tradicionais e de outras populações consideradas 
minoritárias e que são excluídas, entre elas as dos assentamentos e acampamentos, pois demonstram "[...] que o modo de produção capitalista não é onipresente em nossa sociedade [...]" (SANTOS, 2013, p. 169).

Neste sentido, visando apreender outras culturas do trabalho e outras dimensões da formação humana, o GEPTE privilegia a análise da vida cotidiana de povos e comunidades tradicionais, cujo propósito é

[...] contribuir, de alguma maneira, para a autodeterminação dos povos, para o direito de escolher e decidir soberanamente sobre suas formas de produzir a vida. Por meio da pesquisa, o GPTE ${ }^{4}$ quer contribuir com a preservação e o desenvolvimento de práticas que vão de encontro ao modo capitalista de produção da vida social. (TIRIBA; FISCHER, 2015, p. 408).

Ao realizar estudos e pesquisas com os povos e comunidades tradicionais, os participantes do GEPTE se comprometem social e politicamente com suas causas, afinal, como referem Brandão e Borges (2007), inexiste a neutralidade científica em pesquisas.

Segundo Cruz, o termo "tradicional" carrega uma conotação negativa, sinônimo de atrasado, ignorante e improdutivo, "[...] em contraponto com a ideia de um modo de vida e de um modo de produção modernos, marcados pela urbanização, pela industrialização, pela produtividade e pela velocidade [...]" (2013, p. 598). Neste sentido, como mencionado por Silva, os povos e comunidades tradicionais são tratados como arcaicos, ultrapassados e impeditivos ao crescimento do país, já que não se enquadram "[...] aos padrões de modernidade e de progresso" (2011, p. 74), pois suas existências possibilitam a preservação das diversidades biológicas e das diferenças culturais, expressando diariamente uma resistência e possibilitando a construção de novas/velhas perspectivas de relações econômica, social, política e ambiental.

Segundo Cruz, os termos povos e comunidades tradicionais na dimensão teórico-conceitual compõem uma categoria de análise e, na dimensão históricopolítica, se conceituam como categoria da ação política. Neste sentido,

\footnotetext{
${ }^{4}$ A partir de sua criação, já se utilizou duas nomenclaturas para se referir ao Grupo: Grupo de Pesquisa Trabalho e Educação (GPTE) (CAETANO, 2011), e posteriormente, Grupo de Estudos e Pesquisas em Trabalho e Educação (GEPETE) (SANTOS, 2013).
} 
Entender o significado desses termos implica discutir sua origem, sua historicidade e suas diversas formas de apropriação como "categoria de análise" - ou seja, como conceito socioantropológico que busca nomear, caracterizar e classificar certas comunidades rurais - e como "categoria da ação" - ou seja, como identidade sociopolítica mobilizadoras das lutas por direitos. Estas duas dimensões, embora apresentem especificidades, entrecruzam-se nas lutas e disputas em torno dessas categorias, que são, ao mesmo tempo, epistêmicas e políticas. (2013, p. 594-595).

Nosso foco neste texto não é aprofundar a origem e historicidade do conceito povos e comunidades tradicionais - embora o julguemos importante ${ }^{5}$ - e sim, descrever algumas das características que esses povos e comunidades apresentam.

Não desconsideramos que cada povo e comunidade tradicional possua sua singularidade - que deve ser estudada, apreendida e respeitada -, fundada não apenas na região geográfica e climática onde estão inseridos, mas também nos aspectos econômico-culturais. Embora como citado por Souza e Brandão (2012, p. 110), para alguns autores e autoras, o essencial é "[...] diferenciar e desvendar o que cada local pesquisado tem de singular", no presente artigo, trabalharemos com as características comuns aos povos e comunidades tradicionais.

Nesse sentido, Diegues et. al. (2000, p. 18) afirmam que

Numa perspectiva marxista, as culturas tradicionais estão associadas a modos de produção pré-capitalistas, próprios de sociedades em que o trabalho ainda não se tornou mercadoria, em que a dependência do mercado já existe, mas não é total. Essas sociedades desenvolveram formas particulares de manejo dos recursos naturais que não visam diretamente o lucro, mas a reprodução cultural e social como também percepções e representações em relação ao mundo natural marcadas pela ideia de associação com a natureza e a dependência de seus ciclos. [...]. Essas culturas se distinguem daquelas associadas ao modo de produção capitalista em que não só a força de trabalho, como a própria natureza, se transforma em objeto de compra e venda (mercadoria). Nesse sentido, a concepção e representação do mundo natural e seus recursos são essencialmente diferentes.

Diegues et. Al. citam como constitutivos dos povos e comunidades tradicionais "[...] as comunidades caiçaras, os sitiantes e roceiros tradicionais,

\footnotetext{
${ }^{5}$ Evidenciamos que se trata de uma categoria de análise e de ação política produzidas desde o final da década de 1970 e, particularmente, a partir da década de 1990, os termos "povos e comunidades tradicionais" foram sendo apropriados por vários grupos sociais, movimentos sociais, organizações não governamentais (ONGs), mídia, academia e ainda pelo Estado (CRUZ, 2013).
} 
comunidades quilombolas, comunidades ribeirinhas, os pescadores artesanais, os grupos extrativistas e indígenas" (2000, p. 22).

Para Cruz (2013, p. 595-596, itálico do autor), estão incluídos na categoria de povos e comunidades tradicionais os

[...] povos indígenas, quilombolas, populações agroextrativistas (seringueiros, castanheiros, quebradeiras de coco de babaçu), grupos vinculados aos rios ou ao mar (ribeirinhos, pescadores artesanais, caiçaras, varjeiros, jangadeiros, marisqueiros), grupos associados a ecossistemas específicos (pantaneiros, caatingueiros, vazanteiros, geraizeiros, chapadeiros) e grupos associados à agricultura ou à pecuária (faxinais, sertanejos, caipiras, sitiantescampeiros, fundo de pasto, vaqueiros).

Entre as várias características dos povos e comunidades tradicionais, Cruz (2013) enfatiza quatro delas: "a relação com a natureza (racionalidade ambiental) [...]; a relação com o território e a territorialidade [...]; a racionalidade econômicoprodutiva [...] e as inter-relações com os outros grupos da região e autoidentificação" (2013, p. 596-597).

As peculiaridades elencadas pelo autor revelam a produção da existência dos povos e das comunidades tradicionais, e como já apontado por Tiriba e Fischer (2015, p. 408), "[...] mesmo no contexto da acumulação flexível do capital, é possível identificar, nas comunidades tradicionais, características significativas de práticas econômico-culturais fundadas também em mediações de primeira ordem 6" ou em outras palavras, apontam "[...] o enfrentamento dos povos e comunidades tradicionais para resistir às mediações de segunda ordem do capital" (TIRIBA; FISCHER, 2015, p. 411).

Percebemos que os povos e comunidades tradicionais possuem forte vínculo - de pertencimento e de identidade - com o território (CAETANO; NEVES, 2014; CRUZ, 2013; SOUZA; BRANDÃO, 2012). Por isso, extrapolam os limites e as

\footnotetext{
${ }^{6}$ As mediações de primeira ordem "[...] abrangem as relações em cujo quadro tanto os indivíduos da espécie humana como as entrelaçadas condições culturais/intelectuais/morais/materiais cada vez mais complexas de sua vida são reproduzidos segundo a margem de ação sócio-histórica disponível e cumulativamente ampliada" (MÉSZAROS, 2011, p. 212).

${ }^{7}$ Mediações de segunda ordem são "[...] os meios alienados de produção e suas 'personificações'; o dinheiro; a produção para troca; as variedades da formação do Estado pelo capital em seu contexto global; o mercado mundial [...]" (MÉSZAROS, 2011, p. 71).
} 
fronteiras geográficas de habitação, compreendendo também "[...] os ambientes simbólicos, místicos, políticos e econômicos" (SOUZA; BRANDÃO, 2012, p. 111).

Assim, segundo Souza e Brandão (2012), para os povos e comunidades tradicionais, a terra é o lugar que possibilita a produção material da vida, bem como, proteção, abrigo e partilha vidas. Por isso, segundo Caetano e Neves (2014), a sua propriedade, posse, gestão e repartição da produção tende a ser coletiva. A terra oportuniza a plantação e o cultivo de maneira peculiar, revelando uma cultura de trabalho específica dos povos e comunidades tradicionais, que inclusive, expressa a indissociabilidade na relação entre vida, trabalho e terra, bem como, privilegia as relações fundadas na troca e na reciprocidade, "[...] o trabalho familiar, a troca de dias e os mutirões com forma de reprodução" (SOUZA; BRANDÃO, 2012, p. 113).

Desta forma, o núcleo familiar e a relação entre seus membros são valorizadas e os laços de parentesco são fortes (CAETANO; NEVES, 2014; SOUZA; BRANDÃO, 2012). Assim, a vida cotidiana é composta pelos sentimentos de afetividade, amizades, vizinhanças, compadrio, reciprocidade e laços consanguíneos ou de casamento.

Entre os povos e comunidades tradicionais existem uma concepção e uma utilização do tempo que permitem que as pessoas, além de trabalharem, realizem outras atividades como festas, visitas, passeios, conversas, reuniões, lazer, cuidado com as outras pessoas da comunidade, reivindicações referentes à terra, à cultura $e$ à identidade, contemplação da natureza etc. (CAETANO; NEVES, 2014; OLIVEIRA; CAETANO, 2018).

Outra característica desses povos e comunidades é a forte ligação com os antepassados e às raízes históricas. Por isso, existe resistência às mudanças e persiste a produção da vida baseada em ritos e crenças tradicionais (SOUZA; BRANDÃO, 2012). Neste sentido,

Todas essas reflexões vêm reafirmar a autonomia que as comunidades tradicionais têm para a manutenção do saber tradicional e da relação harmônica com a natureza. A persistência e resistência de cada um desses povos ao "novo" reafirma a luta pela manutenção de saberes, refletidos na cultura tradicional. (SOUZA; BRANDÃO, 2012, p. 118). 
Por fim, a partir de Caetano e Neves (2014) e Tiriba e Fischer (2015), mencionamos que é possível observar a presença de elementos da Produção Associada nos povos e comunidades tradicionais. Segundo Tiriba e Fischer (2015, p. 420),

\begin{abstract}
Podemos observar diversos indicadores do trabalho de produzir a vida associativamente, ou melhor, do trabalho associado. O processo se caracteriza por reduzida divisão social e técnica, o que propicia ao conjunto da comunidade o conhecimento de todo o processo de trabalho. Os frutos do trabalho são, majoritariamente, para a manutenção da vida material e simbólica das famílias e das comunidades (sobrevivência) - e não para fins de troca mercantil. A relação com a natureza é de intercâmbio e de equilíbrio vital.
\end{abstract}

Neste sentido, destacamos que, ao conhecer e considerar as características que os povos e as comunidades tradicionais apresentam, o GEPTE, por meio de uma postura crítica e política, tem o intuito de "lançar luz" às suas causas e contribuir na construção de uma nova sociedade em que mulheres e homens produzam suas vidas de forma livre e associada.

\title{
Campo empírico: dizeres e fazeres dos povos e comunidades tradicionais
}

Nessa seção destacamos pesquisas realizadas pelo GEPTE sobre práticas econômico-culturais dos povos comunidades tradicionais do Estado do Mato Grosso. O método utilizado em todas as pesquisas foi o materialismo histórico dialético, pois além de ser postura/concepção de mundo, é um método de apreensão da realidade,

na "[...] busca da transformação e de novas sínteses no plano do conhecimento e no plano da realidade histórica" (FRIGOTTO, 1989, p. 73).

Tal método compreende que a realidade não é algo estanque, mas que se altera cotidianamente, e para apreendê-la e dar conta de seus aspectos, se faz necessário um constante exercício de sair do particular, da "aparência", intentando "atingir a essência” dos fenômenos (KOSíK, 2002, p.16, itálico do autor).

Pensar na possibilidade de outra forma de organização do trabalho pode, por vezes, causar estranheza, considerando nossa imersão no modo de produção capitalista, em que a força de trabalho é alienada em troca de um salário, onde existem hierarquias, relações de competitividade e os meios de produção são 
privados. Tendo como pano de fundo reflexões -produzidas no âmbito do GEPTEacerca de experiências de Produção Associada, pode-se vislumbrar a ampliação da liberdade quanto às atividades realizadas pelos trabalhadores e trabalhadoras, através da opção por determinadas etapas do processo de trabalho a partir da predileção, habilidade e satisfação pessoal. A não exploração de uns sobre os outros e a posse coletiva dos meios de produção também a marcam, pois, inexistindo capataz ou supervisor, cada trabalhador e trabalhadora compreende a importância do seu empenho na produção, privilegiando assim, o coletivo e a solidariedade.

A produção associada enquanto categoria histórica, de acordo com Tiriba (2006, p. 118)

\begin{abstract}
deve ser concebida em dois sentidos. O primeiro vincula-se à constatação (a olho nu) de que a reprodução da classe-que-vivetrabalho, em especial, dos trabalhadores oriundos dos setores populares, requer uma verdadeira produção associada, pressupondo a criação de redes de solidariedade, de colaboração para que, cotidianamente, possam garantir sua sobrevivência. A reprodução ampliada de vida requer a coordenação do esforço coletivo do conjunto de pessoas que compõem a unidade de produção, seja ela unidade doméstica, cooperativa ou de qualquer outro empreendimento econômico. O segundo sentido de "produção associada" caminha no horizonte econômico-filosófico marxista, no qual a mesma é entendida como unidade básica da sociedade dos produtores livremente associados na produção.
\end{abstract}

De acordo com Neves, o trabalho associado pode ser realizado por homens, mulheres e crianças, é autogestionário, não possui regras nem funções definidas durante o processo de produção, favorecendo que as pessoas realizem "[...] a atividade de que mais gostam ou tem mais habilidade, e sempre ajudando uns aos outros" (NEVES, 2012, p. 140), prevalece o repartir equitativo dos frutos excedentes e liberdade individual e é baseado nos seguintes princípios: "[...] solidariedade, cooperação, divisão dos frutos do trabalho, decisões coletivas e democráticas, entre outros" (NEVES, 2012, p. 141).

A reflexão de Guerino (2013) reforça a prevalência do trabalho coletivo junto aos povos e comunidades tradicionais, ao reconhecer que no trabalho associado para a produção da rapadura, participam homens, mulheres, crianças e adolescentes, constituindo-se, pois, em um trabalho coletivo. Os participantes 
ressaltam que a produção da rapadura é relevante por assegurar o sustento, a alimentação e a imunização contra doenças, da mesma forma que, os aproxima dos seus antepassados, face a organização da produção ser a mesma.

Fica evidente que os trabalhadores e trabalhadoras -povos e comunidades tradicionais- preocupam-se em preservar não apenas o trabalho coletivo, mas, o processo produtivo tradicional, ou seja, o mais próximo possível da forma como era realizado pelos seus antepassados. É de fato outra concepção de vida e de mundo, já que, o intuito do trabalho realizado pelos mesmos não é produzir riqueza embora evidenciem o desejo de ter uma qualidade de vida melhor -, mas, assegurar suas existências, sem a submissão ao trabalho assalariado.

Costa $(2017$, p. 135) relata que a produção associada ocorre a partir de práticas coletivas e ancestrais de trabalho, como por exemplo "[...] a partir da 'Troca de Dia', em que uma família ajuda a outra sem que para isso utilize pagamento em dinheiro por este trabalho, mas sim dispondo do seu tempo para ajudar outras pessoas [...]". Por seu lado, Monlevade (2018) ratifica a afirmação anterior ao destacar que o trabalho é o lugar onde se materializa em grande medida, o existir como comunidade. Os produtores e produtoras trabalham de forma coletiva, ajudando-se uns aos outros, desde o momento de cascar a macaxeira até ela se transformar em farinha. A "troca de dia" permite que uns se dediquem exclusivamente a produção de farinha do outro e esse trabalho é "pago" em outro momento, através do mesmo processo.

Outra prática coletiva e ancestral de trabalho associado recebe a denominação de

\footnotetext{
Muxirum que consiste em uma ação coletiva mediante a qual, durante a semana, os moradores realizam atividades laborais, como: plantar, carpir, colher, entre outras, na roça de uma pessoa; no outro dia, essa mesma ação ocorre na roça de outro, e assim por diante. O trabalho que uma pessoa realizaria em uma semana é realizado coletivamente em um dia. Essa prática aumenta a produção, diminui o dispêndio de força física e institui relações de solidariedade, cooperação, amizade, parceria, entre outras (CAETANO; NEVES, 2014, p. 604).
}

O ritmo e o tempo de trabalho são determinados pelas trabalhadoras e trabalhadores, que exercem atividades em que possuem afinidade e que lhes dão 
prazer, socializando saberes. Desta forma, a Comunidade é "[...] um lugar marcado pela vida coletiva, em um espaço compartilhado e em um tempo marcado pelo som da vida e não do relógio" (COSTA, 2017, p. 23). Nesse sentido, Caetano e Neves (2014, p. 601) ressaltam que, nos territórios dos povos e comunidades tradicionais seja possível, ainda hoje, que homens e mulheres "disponham de tempo para contemplar a natureza, muitas vezes expropriado do trabalhador formal. Lá é possível ver as plantas crescerem, ouvir o canto dos passarinhos, deixar a terra correr entre os dedos e provar lentamente o doce das frutas".

Os moradores exteriorizam sua relação com o trabalho, com a vida, com a natureza, os laços de solidariedade, o cuidado que têm entre si, os saberes da experiência, como por exemplo Dona Morena - moradora de uma comunidade tradicional-:

\begin{abstract}
Aqui a gente não sente que tá trabalhando, não é uma coisa de sofrimento o nosso trabalho. Aprendemos que a vida é curta, mas precisa de cuidado, por isso, o trabalho é nossa vida, nosso cuidado com as árvore daqui, com as criança daqui, com os doente daqui, com a nossa rapadura e tudo que você pode enxergar aqui. (GUERINO, 2013, p. 49).
\end{abstract}

As observações empíricas, as entrevistadas/depoimentos e as reflexões consideradas neste texto, esboçam a configuração que a Produção Associada expressa a partir dos povos e comunidades tradicionais, onde são evidenciados os saberes da experiência; a solidariedade (no processo de trabalho, nos mutirões, nas festas, nas relações sociais etc.); a não exploração de uns sobre os outros; a inexistência de competição e a posse coletiva da terra e dos meios de produção entre outros.

\title{
Os saberes da experiência e a produção associada
}

Segundo Azeredo (2013), a produção associada contribui para a produção de saberes, materializada cotidianamente. Essa produção de saberes refere-se ao tempo das águas, à hora de plantar, aos mitos que rodeiam o povo pantaneiro, às plantas medicinais que curam, à produção da canoa e da viola de cocho e a produção de redes. 
Os saberes da experiência são inerentes à produção associada da vida e apontam para uma velha/nova cultura do trabalho. Esses saberes são resultado da experiência (THOMPSON, 1987, 1998) com o trabalho associado, com os meios de produção (terra), com o mundo e com outros trabalhadores (CAETANO; NEVES, 2014, p. 606).

Os saberes da experiência, elencados abaixo, podem "[...] ser o embrião de uma velha/nova cultura do trabalho" (NEVES, 2012, p. 81).

Quadro 1 - Saberes da experiência

\begin{tabular}{|c|l|}
\hline Terra & $\begin{array}{l}\text { Saberes que são transmitidos oralmente de geração para geração, como } \\
\text { por exemplo, a cura de doenças/enfermidades por meio do uso de } \\
\text { plantas, raízes ervas da região. }\end{array}$ \\
\hline Parteiras & $\begin{array}{l}\text { Saberes que ajudavam no nascimento das crianças, que se perderam, } \\
\text { pois, as parteiras morreram e as mais jovens não deram continuidade à } \\
\text { prática. }\end{array}$ \\
\hline Benzedeiras & $\begin{array}{l}\text { Saberes utilizados para auxiliar na cura de doenças/enfermidade. } \\
\text { Também não existem mais, já que não houve pessoas que } \\
\text { perpetuassem essa prática. }\end{array}$ \\
\hline $\begin{array}{c}\text { Crendices e } \\
\text { tradições } \\
\text { populares }\end{array}$ & $\begin{array}{l}\text { Festas religiosas, nas quais materializam a crença e o culto a santos. } \\
\text { O processo de organização dessas festas é ensinado pelos pais, sendo } \\
\text { que homens, mulheres e crianças participam das atividades. }\end{array}$ \\
\hline $\begin{array}{c}\text { Trabalho } \\
\text { Elas crianças aprendem cotidianamente por meio da observação e prática. } \\
\text { como foi o caso do Sr. Justino, um dos participantes da pesquisa, que } \\
\text { aprendeu a lidar com a terra, a ser carpinteiro, pedreiro, marceneiro, } \\
\text { sapateiro etc. }\end{array}$ \\
\hline $\begin{array}{c}\text { Experiências } \\
\text { com o } \\
\text { trabalho } \\
\text { assalariado }\end{array}$ & $\begin{array}{l}\text { As pessoas que saem da Comunidade em busca de emprego e estudo, } \\
\text { quando retornam a ela compartilham as dificuldades vividas, o que } \\
\text { possibilita, entre outras coisas, que outras pessoas desistam de sair da } \\
\text { Comunidade. }\end{array}$ \\
\hline
\end{tabular}

Fonte: Produzido pelo autor e pelas autoras com base em Neves (2012).

Os trabalhadores e as trabalhadoras valorizam os saberes transmitidos pelos mais idosos e, por isso, eles são valorizados e se constituem enquanto estratégia que assegura a perpetuação de saberes constitutivos de uma maneira singular de ser e existir. Nessa perspectiva Thompson (1988, p. 18) assevera que

O aprendizado, como iniciação em habilitações dos adultos, não se restringe à sua expressão formal na manufatura, mas também serve como mecanismo de transmissão entre gerações. A criança faz seu aprendizado das tarefas caseiras primeiro junto à mãe ou avó, mais tarde (frequentemente) na condição de empregado doméstico ou agrícola. No que diz respeito aos mistérios da criação dos filhos, a jovem mãe cumpre seu aprendizado junto às matronas da 
comunidade. O mesmo acontece com os ofícios que não tem um aprendizado formal. Com a transmissão dessas técnicas particulares, dá-se igualmente a transmissão de experiências sociais ou da sabedoria comum da coletividade. Embora a vida social esteja em permanente mudança [...] ainda não atingiram o ponto em que se admite que cada geração sucessiva terá um horizonte diferente.

Azeredo (2013) conclui que o trabalho associado - que remete aos saberes da experiência transmitidos entre gerações -, é um processo educativo em si, uma vez que, além de orientar as discussões quanto ao processo de trabalho, oportuniza que os trabalhadores e trabalhadoras partilhem anseios, angústias, conflitos e sonhos presentes na produção da vida, construindo e mobilizando, assim, saberes e experiências característicos das suas existências.

Os saberes para os povos e comunidades tradicionais remetem a diferentes tempo e espaços onde a cultura, os saberes e os costumes são amálgamas de uma mesma existência material e imaterial.

Os costumes estão claramente associados e arraigados às realidades materiais e sociais da vida e do trabalho, embora não derivem simplesmente dessas realidades. Eles podem preservar a necessidade da ação coletiva, do ajuste coletivo de interesses, da expressão coletiva de sentimentos emoções dentro do terreno e domínio dos que deles coparticipam, servindo com uma fronteira para excluir forasteiros. (THOMPSON, 1998, p. 22).

Faz-se necessário ressaltar que ainda hoje saberes e costumes de outrora dão sentido à existência presente, onde as memórias de um tempo pretérito, sustentam a labuta do ser e existir. Com certa dose de melancolia e saudosismo homens e mulheres evocam o passado onde o vigor do corpo lhes permitia que estes buscassem apenas sal e tecido na cidade. Nesse tempo ido plantavam arroz, feijão, faziam açúcar etc. - levavam uma quantidade superior de mercadorias para serem comercializadas na cidade do que as que lá compravam e hoje, ocorre o inverso-. Contudo, ainda plantam para subsistência, fazem uso das plantas e ervas medicinais, comem banha de porco ao invés de óleo vegetal e muito se orgulham disso (MONLEVADE, 2018).

Pode-se vislumbrar que os saberes da experiência, os costumes e a existência concreta dos povos e comunidades tradicionais tem na produção associada seu corolário. Nessa perspectiva, Brandão assevera que 
[...] elas não são tradicionais porque aos olhos de quem chega opõem-se ao que, segundo 'eles' é: moderno. São tradicionais porque são ancestrais, porque são autóctones, porque são antigos, resistentes anteriores. Porque possuem uma tradição de memória de si mesmos em nome de uma história construída, preservada e narrada no existir em um lugar, por oposição a quem 'chega de fora' (2012, p. 85).

\section{Existência e resistência: o cotidiano nas comunidades tradicionais}

Os moradores das comunidades tradicionais vivenciam uma relação diferenciada com a natureza. Isto porque desfrutam dos seus recursos buscando degradá-la o mínimo possível, não fazendo uso de agrotóxicos e cuidando da terra, reconhecendo que ao protegê-la, estão protegendo a si mesmos (SANTOS, 2013). Nestes territórios o ser humano estabelece forte relação com a natureza, por isso, não só condenando o uso de defensivos agrícolas, mas conservando as áreas arborizadas e mantendo um espaço entre a roça e o rio (COSTA, 2017).

A identidade étnica-cultural pressupõe o existir a partir de uma cosmologia onde os seres humanos, a "Pachamama" ${ }^{8}$ o os demais seres vivos só podem ser compreendidos a partir da existência de uma interdependência e complementariedade indissociável entre os mesmos.

Os saberes ancestrais advindos da experiência secular que designou os traços da identidade indígena Chiquitano, que são saberes legitimados e valorizados pelos Chiquitanos (sendo as anciãs e os anciãos os portadores da maior gama de conhecimento da produção material e imaterial da vida, e que por isso devem ser repassados por estes aos menores, na racionalidade indígena). Formam a unidade de saberes da experiência Chiquitana de como educar suas crianças, jovens e mesmos os adultos; de como ser Chiquitano significa ser natureza, ser o outro, ser o peixe, é falar com a música, dançar a devoção; e, principalmente, de respeitar e desejar o bem-viver de todas e todos como seres essenciais (CAETANO; NEVES; SILVA, 2015 , p. $10-11)$.

\footnotetext{
8 "Vivir Bien es recuperar la vivencia de nuestros pueblos, recuperar la Cultura de la Vida y, recuperar nuestra vida en completa armonía y respeto mutuo con la madre naturaleza, con la Pachamama, donde todo es VIDA, donde todos somos uywas, criados de la naturaleza y del cosmos, donde todos somos parte de la naturaleza y no hay nada separado, donde el viento, las estrellas, las plantas, la piedra, el rocío, los cerros, las aves, el puma, son nuestros hermanos, donde la tierra es la vida misma y el hogar de todos los seres vivos" (CESPEDES, 2010, p. $10-11$ )
} 
A igualdade e a solidariedade são valores enfatizados e vivenciados pelos povos e comunidades tradicionais, prevalecendo nesses territórios o respeito mútuo, a cooperação, a autogestão e democracia nas decisões comunitárias. Esses valores estão atrelados às relações de parentesco (família), religiosidade e o trato com a terra (SANTOS, 2013).

As relações sociais pautadas na solidariedade e na igualdade existem para além das relações de trabalho, pois se dão em outras dimensões da existência humana, como por exemplo, no ato de comprar alimentos, organizar a casa, cuidar da roça e dos animais quando algum membro da comunidade, por razões de saúde não pode (MONLEVADE, 2018). Tudo isso a partir de outra relação com o outro, com a outra, relação essa tão presente no cotidiano dos povos e comunidades tradicionais.

A partir da produção associada e da criação de grupos/associações para a produção, as mulheres ampliaram a capacidade de compra e consumo $^{9}$ notadamente de alimentos, vestuário e produtos de higiene - Contudo, a possibilidade de produzir de forma associada, está para além das condições de consumo, já que também está relacionada à saída exclusiva do trabalho doméstico e em suas roças, de ter seu trabalho reconhecido, de interagir com outras mulheres e com seus saberes e conhecer outras realidades através dos encontros realizados em diversas regiões do país.

Neves (2017) ressalta a ocorrência de mudanças consideráveis no tocante a existência no território dos povos e comunidades tradicionais, resultantes em grande medida da mecanização do trabalho do campo, do avanço do agronegócio e das mudanças político-econômico e sociais do nosso país. Neste sentido, conforme a autora (2017, p. 261, itálico da autora),

\footnotetext{
9 "[...] o primeiro pressuposto de toda a existência humana e também, portanto, de toda a história, a saber, o pressuposto de que os homens têm de estar em condições de viver para poder fazer história. Mas, para viver, precisa-se, antes de tudo, de comida, bebida, moradia, vestimenta e algumas coisas mais. O primeiro ato histórico é, pois, a produção dos meios para a satisfação dessas necessidades, a produção da própria vida material, e este é, sem dúvida, um ato histórico, uma condição fundamental de toda a história, que ainda hoje, assim como a milênios, tem de ser cumprida diariamente, a cada hora, simplesmente para manter os homens vivos" (MARX; ENGELS, 2007, p. 32 $-33)$.
} 
[...] as mulheres do campo além de lidarem, historicamente, com desigualdade de gênero, discriminação e exclusão social, tem o seu bem viver desafiado, cotidianamente, pelo agronegócio, pela degradação da natureza e pela sedução de seus filhos pelo trabalho assalariado.

Ainda assim, as camponesas têm resistido e lutado para romper com os muros, com as cercas e com as desigualdades de gênero, em busca de melhores condições de vida para elas, suas famílias e para outras mulheres.

Costa (2017) argumenta que, embora persista vestígios da divisão sexual do trabalho nas comunidades tradicionais, as relações sociais entre mulheres e homens acontecem de forma mais solidária, humana, dialógica e participativa. Assim, as marcas dessa divisão são minimizadas pela colaboração e solidariedade na produção da existência.

\section{Considerações finais}

No decorrer da reflexão acerca dos achados expressos pelas pesquisas do GEPTE/UFMT, efetivada anteriormente, não tratamos das contradições presentes na existência dos povos e comunidades tradicionais. Cumpre destacar, que a contradição é característica imanente ao ser humano e o existir em sociedade, notadamente a partir do materialismo histórico dialético. Nesse sentido não a negamos, mas considerando-se os objetivos e limites deste texto não nos debruçamos sobre essa dimensão de maneira exaustiva.

Parte considerável das contradições vivenciadas pelos povos e comunidades tradicionais emergem a partir da presença devastadora - notadamente no Estado de Mato Grosso - do agronegócio que, em sua ânsia pelo lucro, degrada cotidianamente a natureza, o território e a existência dos povos e comunidades tradicionais.

Apesar das contradições e limites expressos pela produção associada da vida a partir dos povos e comunidades tradicionais, os resultados de pesquisas indicam a possibilidade - ainda que imersos nas contradições engendradas pelo modo de produção capitalista - de que essas novas/velhas experiências contribuam para a construção da sociedade dos produtores livremente associados. 
Percebemos que os povos e comunidades tradicionais são possuidores de saberes da experiência/ancestrais/milenares, o que Ihes oportuniza por um lado, definir o que, como e quando plantar; a potencialidade e o cuidado com a terra; o cultivo sem o uso de agrotóxico; a utilização das e ervas na medicina popular; o estabelecimento de relações sociais pautadas na solidariedade etc. e por outro lado, compreender a realidade em que estão inseridos de forma crítica e propositiva.

A produção da existência nos povos e comunidades tradicionais acontece por meio do trabalho coletivo, do bem viver em comum, da cultura do muxirum, da solidariedade, da dádiva da partilha, da repartição igualitária dos frutos do trabalho, da reciprocidade, da democracia, da terra coletiva, da manutenção dos costumes e tradições, do plantio e roça coletivos, dos laços de pertencimento, enfim, da produção da existência que em alguma medida questiona os ditames da sociedade capitalista.

Por isso, o trabalho não é estranhado, as pessoas são proprietárias dos meios de produção e não almejam lucro, a propriedade e a posse da terra, a gestão e a repartição da riqueza são coletivas e inexiste a dominação, a subordinação, a hierarquia, a exploração da força de trabalho de outrem, a acumulação, a competitividade e a obtenção da mais-valia.

Apesar de serem vistos como sujeitos responsáveis pelo impedimento do "progresso" e do desenvolvimento econômico do país, os povos e as comunidades tradicionais têm protagonizado uma história de resistência, de esperança e de contraposição à lógica, aos valores, às ideologias e ao modo de produção capitalista, trazendo consigo, nas palavras de Silva (2015, p. 142), uma "alternativa econômica-social composta na racionalidade do território comum e nos seres livres que se associam para o bem-viver de todos, sem hierarquização dos privilégios".

\section{Referências}

ANTUNES, Ricardo. Os Sentidos do Trabalho: ensaio sobre a afirmação e a negação de conflitos. São Paulo, São Paulo: Boitempo, 2009a.

. SÉCULO XXI: Nova era da precarização estrutural do trabalho? In: ANTUNES, Ricardo; BRAGA, Ruy. INFOPROLETÁRIOS: degradação real do trabalho virtual. São Paulo: Boitempo, 2009b. 
; ALVES, Giovanni. As mutações no mundo do trabalho na era da mundialização do capital. In: Educação \& Sociedade, Campinas, v. 25, n. 87, p. 335-351, maio/ago. $2004 . \quad$ Disponível em: http://www.scielo.br/pdf/es/v25n87/21460.pdf. Acesso em: 9 jul. 2018.

AZEREDO, Eloísa Rosana de. A associação comunitária e de micro produtores rurais de São Pedro de Joselândia: um estudo sobre trabalho e produção de saberes. Cuiabá, MT, 2013, 169f. Dissertação (Mestrado em Educação) Universidade Federal de Mato Grosso, Cuiabá, MT, 2013.

BRANDÃO, Carlos Rodrigues; BORGES, Maristela Correa. A pesquisa participante: um momento da educação popular. Revista de Educação Popular, Uberlândia, v. 6, p. 51-62, jan./dez. 2007. Disponível em: http://www.seer.ufu.br/index.php/reveducpop/article/view/19988/10662. Acesso em: 9 jul. 2018.

; LEAL, Alessandra. Comunidade tradicional: conviver, criar, resistir. Revista da ANPEGE, v. 8, n. 9, p. 74-91, jan./jul., 2012. Disponível em: http://ojs.ufgd.edu.br/index.php/anpege/article/view/6518/3510. Acesso em: 9 jul. 2018.

CAETANO, Edson. Considerações sobre o binômio trabalho e educação: um olhar pantaneiro. Trabalho necessário, ano 9, n. 13, edição especial, p. 1-17, 2011. Disponível em: http://www.uff.br/trabalhonecessario/images/TN13UFMT.pdf. Acesso em: 9 jul. 2018.

; NEVES, Camila Emanuella Pereira. Entre cheias e vazantes: trabalho, saberes e resistência em comunidades tradicionais da baixada cuiabana. Revista de Educação Pública, v. 23, n. 53/2, p. 595-613, maio/ago, 2014. Disponível em: http://periodicoscientificos.ufmt.br/ojs/index.php/educacaopublica/article/view/1756/1 324. Acesso em: 9 jul. 2018.

; NEVES, Camila Emanuella Pereira; SILVA, Marília de Almeida. A produção da vida material e imaterial em comunidades chiquitanas e quilombolas em Mato Grosso: uma nova/velha forma de existência. Polis Revista Latinoamericana, n. 40, 2015, p. 1 -14, maio, 2015. Disponível em:

file:///C:/Users/House/Downloads/polis-10699\%20(2).pdf. Acesso em 18 jul. 2018.

CESPEDES, David Choquehuanca. Hacia la reconstrucción del Vivir Bien. América Latina en Movimiento, n. 452, p. 6 - 13, 2010. Disponível em: http://www.plataformabuenvivir.com/wpcontent/uploads/2012/07/ChoquehuancaReconstruccionVivirBien2010.pdf. Acesso em: 18 jul. 2018.

COSTA, Janaina Santana da. Espaços de Esperança: a produção associada da vida na Comunidade São Benedito Remanescente dos Quilombos - Poconé-MT. Cuiabá, MT, 2017, 217f. Tese (Doutorado em Educação) - Universidade Federal de Mato Grosso, Cuiabá, MT, 2017. 
CRUZ, Valter do Carmo. Povos e comunidades tradicionais. In: CALDART, Roseli Salete; PEREIRA, Isabel Brasil; ALENTEJANO, Paulo; FRIGOTTO, Gaudêncio (Orgs.). Dicionário da Educação do Campo. Rio de Janeiro, São Paulo: Escola Politécnica de Saúde Joaquim Venâncio, Expressão Popular, 2013.

DIEGUES, Antonio Carlos; ARRUDA, Rinaldo Sergio Vieira; SILVA, Viviane Capezzuto Ferreira da; FIGOLS, Francisca Aida Barboza; ANDRADE, Daniela. Os saberes tradicionais e a biodiversidade no Brasil. Brasília: Ministério do Meio Ambiente, dos Recursos Hídricos e da Amazônia Legal; São Paulo: USP, 2000.

ENGELS, Friedrich. Sobre o papel do trabalho na transformação do macaco em homem. In: ANTUNES, Ricardo (Org.). A Dialética do trabalho. São Paulo: Expressão Popular, 2013.

FRIGOTTO, Gaudêncio. O enfoque da dialética materialista histórica na pesquisa educacional. In: FAZENDA, Ivani (Org.). Metodologia da pesquisa educacional. São Paulo: Cortez, 1989.

. Prefácio. In: TIRIBA, Lia; PICANÇO, Iracy (Orgs.). Trabalho e Educação: arquitetos, abelhas e outros tecelões da economia popular solidária. São Paulo: Idéias \& Letras, 2010.

GUERINO, Mariana de Fátima. O movimento dos saberes na produção da vida na comunidade quilombola Campina de Pedra. Cuiabá, MT, 2013, $139 f$. Dissertação (Mestrado em Educação) - Universidade Federal de Mato Grosso, Cuiabá, MT, 2013.

KOSÍK, Karel. Dialética do concreto. Rio de Janeiro: Paz e Terra, 2002.

MARX, Karl; ENGELS, Friedrich. A ideologia alemã. São Paulo: Boitempo, 2007. . Manuscritos econômico-filosóficos. São Paulo: Boitempo, 2008.

Processo de trabalho e processo de valorização. In: ANTUNES, Ricardo (Org.). A Dialética do trabalho. São Paulo: Expressão Popular, 2013.

MÉSZÁROS, István. Para além do capital: rumo a uma teoria da transição. São Paulo: Boitempo, 2011.

MONLEVADE, Ana Paula Bistaffa. Comunidade Tradicional Raizama em Jangada/MT: produzindo a existência associadamente por meio de enxadas, ralos, sucuris e torradeiras. Cuiabá, MT, 2018, 207f. Tese (Doutorado em Educação) Universidade Federal de Mato Grosso, Cuiabá, MT, 2018.

NEVES, Camila Emanuella Pereira. A produção associada em Capão Verde: entre bananas, saberes e utopias. Cuiabá, MT, 2012, 181f. Dissertação (Mestrado em Educação) - Universidade Federal de Mato Grosso, Cuiabá, MT, 2012. 
. A Amélia que era mulher de verdade? Produção associada e relações de gênero em comunidades tradicionais de Cáceres/MT: para além estereótipos e preconceitos. Cuiabá, MT, 2017, 305f. Tese (Doutorado em Educação) Universidade Federal de Mato Grosso, Cuiabá, MT, 2017.

OLIVEIRA, Anatália Daiane de Oliveira; CAETANO, Edson. "Tempo, tempo, tempo, tempo": concepção e utilização no povo Puruborá da aldeia Aperoi em Rondônia e em comunidades Tradicionais de Mato Grosso. Revista Igarapé, Porto Velho, v. 5,

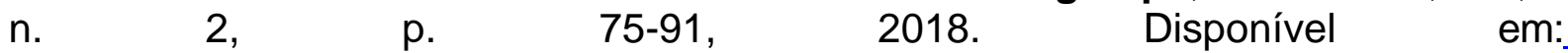
http://www.periodicos.unir.br/index.php/igarape/article/view/2717/2164. Acesso em: 12 jun. 2018.

SANTOS, Lirian Keli dos. Trabalho, produção associada e produção de saberes na comunidade tradicional Imbê-MT. Cuiabá, MT, 2013, 184f. Dissertação (Mestrado em Educação) - Universidade Federal de Mato Grosso, Cuiabá, MT, 2013.

SAVIANI, Dermeval. Trabalho e educação: fundamentos ontológicos e históricos. Revista Brasileira de Educação, v. 12, n. 34, p. 152-180, jan./abr. 2007. Disponível em: http://www.scielo.br/pdf/rbedu/v12n34/a12v1234.pdf. Acesso em: 19 fev. 2016.

SILVA, Regina Aparecida da. Do invisível ao visível: o mapeamento dos grupos sociais do estado do Mato Grosso - Brasil. São Carlos, SP, 2011, 221f. Tese (Doutorado em Ecologia e Recursos Naturais) - Universidade Federal de São Carlos, São Carlos, SP, 2011.

SOUZA, Angela Fagna Gomes de; BRANDÃO, Carlos Rodrigues. Ser e viver enquanto comunidades tradicionais. Mercator, Fortaleza, v. 11, n. 26, p. 109-120, set./dez. $2012 . \quad$ Disponível em: http://www.mercator.ufc.br/index.php/mercator/article/viewFile/724/445. Acesso em: 9 jul. 2018.

TIRIBA, Lia. Cultura do trabalho, produção associada e produção de saberes. Educação Unisinos, São Leopoldo, v.10, n. 2, p. 116-122, mai./ago. 2006. Disponível em: file:///C:/Users/House/Downloads/6050-18558-1-SM.pdf. Acesso em: 6 jul. 2018.

Cultura do trabalho, autogestão e formação de trabalhadores associados na produção: questões de pesquisa. Perspectiva, Florianópolis, v. 26, n.1, p. 89-94, jan/jun. 2008. Disponível em: https://periodicos.ufsc.br/index.php/perspectiva/article/viewFile/10295/9566. Acesso em: 9 jul. 2018.

; FISCHER, Maria Clara Bueno. Espaços/tempos milenares dos povos e comunidades tradicionais: notas de pesquisa sobre economia, cultura e produção de saberes. Revista de Educação Pública, Cuiabá, v. 24, n. 56, p. 405-428, maio/ago. 2015. http://periodicoscientificos.ufmt.br/ojs/index.php/educacaopublica/article/view/2440/1 706. Acesso em: 9 jul. 2018. 
; PICANÇO, Iracy. O trabalho como princípio educativo no processo de produção de uma "outra economia". In: TIRIBA, Lia; PICANÇO, Iracy (Orgs.). Trabalho e Educação: arquitetos, abelhas e outros tecelões da economia popular solidária. São Paulo: Idéias \& Letras, 2010.

THOMPSON, Edward Palmer. Costumes em comum. Estudos sobre a cultura popular tradicional. São Paulo: Companhia da Letras, 1998.

Recebido em: 29 de julho de 2018.

Aprovado em: 21 de setembro de 2018.

Publicado em: 22 de novembro de 2018. 